\title{
Understanding Global Digital Inequality: The Impact of Government, Investment in Business and Technology, and Socioeconomic Factors on Technology Utilization
}

\author{
Rasool Azari \\ University of Redlands \\ rasool_azari@redlands.edu
}

\author{
James B. Pick \\ Universtiy of Redlands \\ james_pick@redlands.edu
}

\begin{abstract}
This paper presents a model of governmental, investment, social, and economic factors that influence technological utilization for 110 countries. Structural equation modeling is applied to conceptualize and test the model. This model uses latent and observable variables and the application tests the hypothesis that technology use can be accounted for in a multidimensional model composed of four factors: Government Support/Legal Framework/Openness, Investment in Business and Technology, Socioeconomic Level, and Technology Utilization. Findings indicate a critical pathway of influences between the factors of government support/legal framework/openness, socioeconomic level, and technology utilization. The results are important because they model complex path relationships between factors identified in the literature, but not previously available for SEM analysis. The paper suggests policy steps for national governments of developed and developing nations especially for policies stressing investment in ICT, strengthening of $R \& D$, societal openness, a strong legal system, prioritization of ICT, and betterment of education.
\end{abstract}

Keywords: Global digital divide, socioeconomic factors, technological utilization, government investment, structural equation modeling

\section{Introduction}

Over the past decades technological development has been reshaping the material basis of our society and economy in an ever-increasing pace.
The rapid development and diffusion of information technologies have altered the process of production, raised productivity, and improved living standards in many countries around the world. This transformation is taking place on a global basis. Yet, there is evidence that this revolution is still in its beginning stages and its effects are not yet well understood and predictable. But there is general consensus that the advances in the information technology are global, irreversible, and will continue to transform the way we live and work. As globalization pressures countries, especially developing ones, to keep pace with the competitive forces, it is becoming clear that physical access to ICT is only a small part of the problem. Creating an environment that fosters innovation and knowledge sharing is the key to success [8].

One issue, which frequently surfaces, is the question of how these sweeping changes will affect the fabric of our lives. As Wilhelm [43] puts it:" Technology is not the problem-it's the use of technology that can empower or control, unite or divide; we need to recover the ideas of social justice and fairness that have been lost in the rush to make things faster and cheaper." Will the revolutionary advances of the information and communication technology (ICT) widen the "digital divide" and increase the gap of inequality in technology, which already is prevalent throughout societies or will we be able to direct these forces to work more equitably for the benefit of everyone? This is the daunting challenge the global economy face. The recent technological innovations and their impact on economic performance, especially in industrial countries, seem not only to affect the way we live and work but they also seem to determine the course of action in our society. For 
example, the rate of diffusion of the Internet has been very much dependent on social institutional systems rather than "the outcome of the operation of technological [and market] advances only" [44, p.29]. Technology alone does not determine society and neither can society script the activities of technological innovation; technological change and innovation depend on many complex patterns of interaction, including individual inventiveness and entrepreneurship [14].

This paper has the objective to better understand the relationships of governmental, business and technology investment, and socioeconomic factors with information technology utilization. Its implications impact how government, business, and citizenry are involved with and support the utilization of IT. It raises relevant questions that may help policy makers and experts to identify and address potential and already developing social and economic problems based on the recent changes and it may help to increase the social dialogue and regional partnership among countries, employers, workers, governments, and civil society regarding the advances in technology. Digital inequality is defined for this study as differences between countries in their citizens' access to, training on, and knowledge of information technology. Technology utilization is taken here as an indicator of digital inequality. Another concept examined in the literature and by policy makers is digital divide, which in the present study represents the gap between digitally advanced and digitally trailing nations.

\section{Literature Review}

The rapid development of new technologies in the information age is a source of problems for the old socioeconomic structures "...until society and social institutions are able to match perfectly with them" [32, p. 126]. "If there is technological advance without social advance, there is, almost automatically, an increase in human misery" [24]. It is reported that less than one sixth of the world's population utilizes technology in a way that makes a difference in their lives and those with greater Internet access had also greater access to education, income and other resources that help them succeed economically [19]. Fortunately, the advances in technology and the risks associated with its applications can be shaped by social and political choices. Society through government intervention and policy changes can stall or accelerate the process of technological change. There is sufficient evidence from the literature that both government intervention and private sectors involvement are crucial in alleviating the digital divide [4] [23] [26] [35] [37] [42] [44]. James [26] rejects the view that digital divide will be alleviated without government intervention. In a comparative study between China and India, Raven [36, p.91] argues that even though both countries had access to the information technology at about the same time, each has taken a different path which dramatically involves both government and business contributions; as he puts it: "These approaches are based on a number of factors, including government initiatives and focus, infrastructure building, experience and understanding of business operations, and culture, among others."

One phenomenon related to technological change which is depicted in our structural path diagram and received the attention of many labor and trade economists [4] [5] [10] [18] [25] [27] [31] is the emergence of wage divergence in the late 1970s and early 1980s. It is widely believed that the development of the new technology increased the demand for skilled workers, thereby increasing the wage differential between skilled and unskilled workers [9]. Baldwin [5] indicated that none of the economic forces alone can account for the observed wage inequality. They emphasized that education-biased technical progress played important roles in bringing about the increase in wage inequality during the $1980 \mathrm{~s}$ and 1990s. Autor et al. [3] agrees that education is playing a crucial role in skill-based technological change such as computerization. Some refer to trade as the reason for the wage inequality, while others argue that technological change is the primary explanation for the widening gap in inequality of wages--the so called skilled biased technical change. Even though empirical evidence from the literature on wage inequality is inconclusive and fragmented [18], there is however, increasing consensus that technological change and innovation is the primary factor for the increasing gap in wages. In another study, Ono [33] examines information technology usage in five countries: U.S., Sweden, Japan, South Korea, and Singapore. He concludes: "Our findings generally suggest that differences in IT usage along demographic and socioeconomic dimensions reflect the extent of differences in other areas of the economy and society" and that the gaps in IT usage reflect pre-existing social and economic inequalities. As a result, Socioeconomic Level and Technology Utilization influence one another in a bidirectional way (see Figure 1, our structural equation model).

Robison and Crenshaw [37] applied 3-step regression methodology to a sample of countries in the early 1990s to identify influences on internet capacity, defined as the number of internet hosts per capita. 
Modernization theory of development underpins the study. Findings show significant influence of development level and political freedom on internet capacity, while education broadly conditions other variables in the model. Teledensity is validated as a significant proximate determinant, and would be considered part of the present factor INVBT. The other conceptual model factors are present. Sharma and Gupta [38] developed a conceptual study that contains variables for all of the factors in the present model, although they are arranged differently. The relevant outcome variable is "digital divide," which is accompanied by 11 other social and economic outcomes such as marginalization and impact on taxes. Pick and Azari [34] analyzed the impacts of 13 independent variables on ICT usage, expenditure, and infrastructure. The independent variables were not grouped, but if categorized to the present model, would be evenly divided between GSLO, INVBT, and SOCLEV. Results indicate that for developed nations, variables in the INVBT factor were most significant in influencing TECUTIL, while for developing nations, the pathway from GSLO to SOCLEV to TECUTIL is supported. Since regression was utilized, the present model's pathways could not be statistically validated but only inferred. In sum, these three studies include the hypothesized model's factors, and some of the pathways are justified.

Guillen and Suarez [23] examines the relationship of democracy and the Internet and argues that democratic regimes enable a faster growth of the Internet than authoritarian or totalitarian regimes. One of his hypotheses is: "The more democratic the polity, the greater the internet use [23, p. 689]." Government can try to control the Internet by monopolizing control. If there is less government control of it, the Internet flourishes, and it is associated with greater democracy and civil liberties [31]. Furthermore, Norris et al. [31, p. 61] claims that "all the selected indicators of economic development, human capital, and democratization proved to be strongly and significantly related to use of the Internet...the proportion of the population online in each country [is] significantly related to levels of per capita GDP, R\&D spending, literacy and secondary education, and level of democratization, according to the available measures." A cross-country study of internet use and mobile phone diffusion [17] points to importance of competition policy for developing nations. It indicates that long-term infrastructure such as for phones may be more important for the digital divide than access. Wallsten [40] studied the impacts of regulatory policies on growth of internet services in developing countries. He found regulation to be inhibitory to ICT -- some regulatory policies tend to reduce the number of internet users while others lead to higher internetaccess prices. Van Dijk [39, p.6] contends that "Divides are byproducts of old inequalities, digital technology is intensifying inequalities, and new inequalities are appearing." For this reason, variables on government openness and regulation are included as part of the government latent factor in the present model.

Case studies of Estonia [20] and Egypt [41] provide support that GSLO affects SOCLEV for midlevel and developing countries. In 1991, when Estonia became independent from the former Soviet Union, successive governments emphasized development off information technologies and the internet. The government introduced a series of programs starting in the mid to late 1990s aimed at creating openness in the society, including constitutional rights of internet access for all citizens, a portal linked to all government websites, and open access to draft legislative bills and amendments. The Tiger Leap program sought for all school children to have Internet access and skills and the "Look@ the World" program which aimed to provide training on the internet as well as open access to reach 90 percent of the citizens. During the period, the country achieved remarkable advances in per capita income and education level of technology, although some challenges remain including deficits in ICT workforce, maintenance of top government leadership interest, and stimulating the export industry in technology [20].

In a study of internet diffusion in five North African nations, Danowitz et al. [17] identified the key barriers as low income growth, limited social and economic integration in the region, an unabsorbed labor surplus, and inability to develop the necessary level of consumption. In a national, longitudinal study of German households, Korupp and Szydlik [28] found that computer and internet use were influenced positively by income and male gender and negatively by living in a single household. In the families pointed out that computer and internet use is often driven by children, leading to generational and age effects. Although based on the household unit of analysis, the findings point to both a pathway from Socioeconomic Level to Technology, and also a pathway in the opposite direction, particularly mediated by technology being available to children. Chinn and Fairlie [15] examined differences in internet and personal computer penetration for 161 countries from 1999-2001, using regression and gap analysis. This SOCLEV to TECUTIL pathway was supported, since significant variables were income per capita, followed by years of schooling, illiteracy, dependency ratios, urbanization, infrastructure, and regulatory quality. 


\section{Research Questions}

Research in the area of the digital divide has addressed many questions: What factors influence variations in the utilization of technology? Is digital divide part of the old inequalities? Is technology partly a generic problem of inequality and accessibility? What is the influence of socioeconomic factors, governmental policies, and the private sectors on the usage of technology? What are the differences in socioeconomic, governmental, and accessibility influences on ICT infrastructure quality between developing and developed nations?

The present study seeks to answer the following research questions.

Research Question 1. Is the overall model that includes the factors, investment in business and technology, government support and legal framework and openness, socioeconomic level, and technology utilization are significant in modeling the observed endogenous variables? The model applies for the overall sample and subsamples of developed and developing nations.

Research Question 2. Do the factors of investment in business and technology (INVBT) and government support, legal framework, and societal openness (GSLO) significantly co-vary with each other? This applies for the overall sample and two subsamples.

Research Question 3. Does government support, legal framework, and societal openness (GSLO) significantly influence socioeconomic level (SOCLEV)? This applies for the overall sample and two subsamples.

Research Question 4. Does socioeconomic level (SOCLEV) significantly influence technology utilization (TECUTIL)? This applies for the overall sample and two subsamples.

Research Question 5. Does the factor, investment in business and technology (INVBT) significantly influence technology utilization (TECUTIL)? This applies for the overall sample and two subsamples.

\section{Methodology}

This research is based on structural equation modeling (SEM), which is an integrated modeling approach that utilizes factor analytic methods to form factors based on observed endogenous variables [11]. SEM fits the model to data for the observed variables by adjusting the specified relationships between the factors in order to estimate the covariances of the observed variables [8] [11]. For SEM, the study utilized AMOS software [1]. The measurement model describes relations between the observed and unobserved variables. The observed indicator variables are designed to measure unobserved latent variables. The structural model defines relations among the unobserved variables. The application tests the hypothesis that the level of information technology in a country can be modeled by the follow four latent factors: Investment in business and technology (INVBT), Government support, legal framework, and societal openness (GSLO), Socioeconomic level (SOCLEV), and Technology utilization (TECUTIL). Each latent variable (factor) is measured by five or six observed endogenous variables. The variables specific justifications are not included due to space limitations.

- Investment in business and technology (INVBT)

is measured by Technological readiness

(TECHREDY), University-industry research collaboration (UNIVINDCOL), Venture capital availability (VENCAPAV), Financial Market Sophistication (FINMRKTS), Foreign direct investment (LFDIPC, measured per capita as a log), and Level of scientific research (SCIENRES).

- Government support, legal framework, and societal openness (GSLO) is measured by Government prioritization of ICT (GPRIORIT), Number of Procedures Required to Start a Business (NPROCSB), Freedom of the Press (FRDMPRSS), Laws relating to ICT (ICTLAWS), and Intellectual property protection (INTLPROP).

- Socioeconomic level (SOCLEV) is measured by QEDUSYS (Quality of the education system), GENRPED (Gross enrollment ratio, Primary education), PFEMLAB (Percent females age 15-64 in the labor force), LGNIPC ( $\log$ of gross national income per capita), and dependency ratio (DEPRTO). The latter is defined as the ratio of children plus elderly divided by the working age population.

- Technology utilization (TECUTIL) is measured by Internet users per 100 population (INTUSERS), Internet servers per million population (INTSERAS), Mobile phone subscribers capita (MOBPHSUB), Personal computers per capita (PERSCOMP), and Log of internet hosts per capita (LINTHOST).

The conceptual framework is that social, economic, governmental, investment, and policy characteristics affect the utilization of technology at the country unit of analysis. The measurement model is partially based on a framework developed by the World Economic Forum in collaboration with Harvard's Center for International Development [19], which examined the network readiness index of nations according to three dimensions: ICT 
environment, readiness of a country, and actual usage of ICT, comprised of base variables. The data are collected from Global Information Technology Report [19] and the World Development Indicators 2007 [42].

The overall structured equation model and the component factors are shown in Figure 1. The overall model is supported by a number of studies mentioned in the literature review [20] [34] [37] [38]. GSLO and INVBT are known to be closely associated and in the model have a covariance relationship. A unidirectional relationship from GSLO to SOCLEV is supported by case study research [20] [41], while the one from INVBT to TECUTIL is supported empirically by Chinn and Fairley [15], Azari and Pick [4] and Pick and Azari [34]. Many studies have supported a two-directional relationship between SOCLEV and TECUTIL [15] [17] [28] [34]. The authors were not able to find literature support for the relationship between INVBT and SOCLEV, so that link is not included in the conceptual model. The direct relationship of GSLO on TECUTIL has been reported in the literature [34], but the present model does allow for an indirect relationship between the two factors through the intermediate of SOCLEV, so it was felt that including the direct relationship is not necessary.

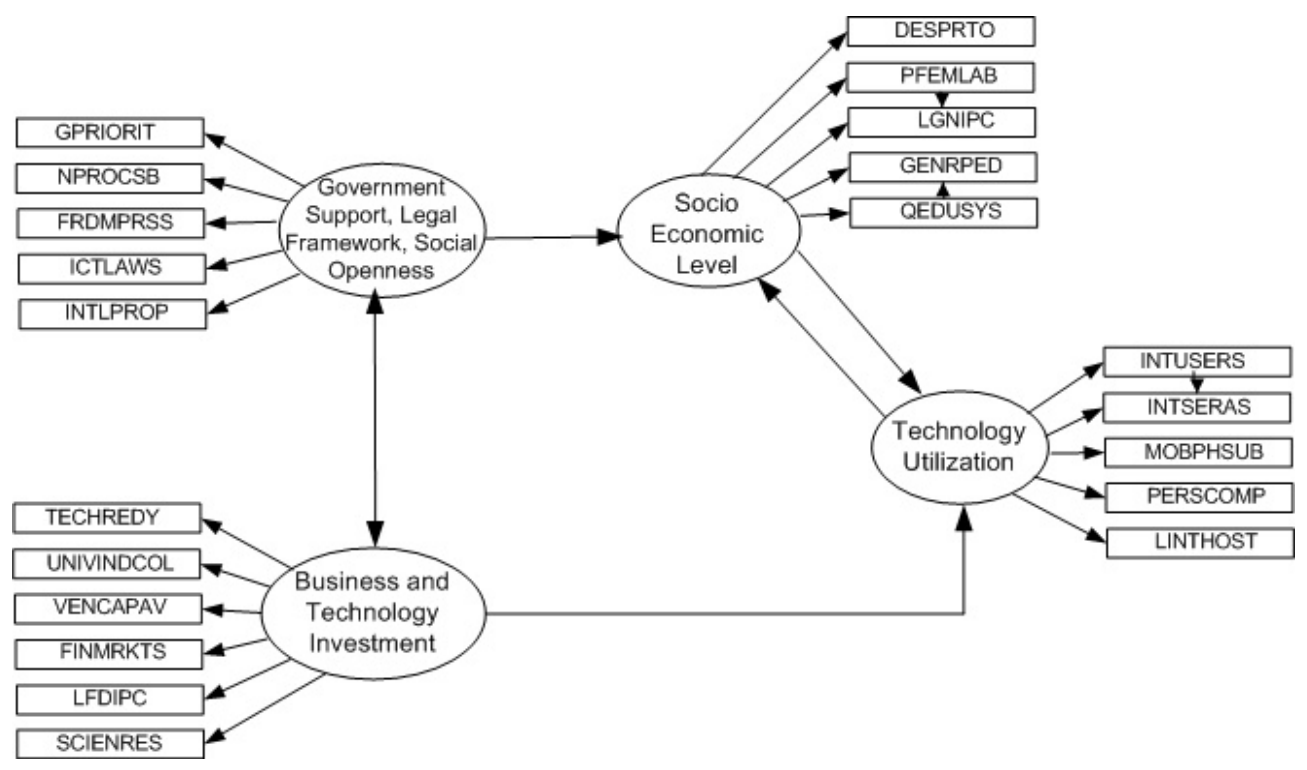

Figure 1. Structured Equation Model of Technology Utilization, with Observed Endogenous Variables (note: error terms not shown for endogenous variables)

A number of pre-processing procedures were conducted on the data. Variables giving raw totals for the country were converted to per capita. For several variables with large variances, in particular LGNIPC, LFDIPC, and LINTHOST, the per capita attribute was adjusted by the natural log. Since AMOS does not have a robust missing value feature, a limited number of variable values (less than 15) were inputted by substituting the average values for a group of similar countries in the sample. In the case of the huge foreign direct investment (FDI) for lightly populated Luxembourg, its FDI per capita was replaced with the average per capita value based on a subsample of similar European nations. This outlying irregularity arises because that country records FDI for multiple other major countries the funds from which flow through it. After preprocessing, the total sample size is 110 . It is evenly divided into subsamples of 56 developing nations, defined as those with gross national income per capita equal or greater than $\$ 3,400$, and 54 developed countries, i.e. those with GNIPC less than $\$ 3,400$.

\section{Findings}

The results for the overall sample indicate good support for the model overall, according to two of three indices (see Table 1). As seen in Figure 2, there is significant covariance between INVBT and GSLO. Part of the explanation is that a country that has a strong and fair legal framework, openness, clear procedures, and governmental interest in furthering ICT is also one likely to have healthy internal and 
foreign investment, $\mathrm{R} \& \mathrm{D}$, and government-university research collaboration. The importance of these openness factors in fostering technology investment and growth was noted for developing countries by Baliamoune-Lutz [5]. Guillen [23] found that democratic regimes had associated growth of internet technologies and usage. The influence of GSLO on SOCLEV and the influence of INVBT on TECUTIL are not significant. For the latter, the non-significant relationship is inverse. However, there is strong influence of SOCLEV on TECUTIL, although not in the reverse direction. This strong impact of socioeconomic factors corresponds has been noted by a number of technology levels in country-sample studies [13] [30] [31], although not found in others [4] [6] [34]. However, none of the cited studies utilized SEM methodology, which allows for enhanced model dimensions.

\begin{tabular}{|c|c|c|c|c|c|}
\hline & & & Good & s of Fit Inc & \\
\hline & $\mathrm{N}$ & $\mathrm{Chi}^{2}(\mathrm{p}, \mathrm{DF})$ & $\mathrm{Chi}^{2} / \mathrm{DF}$ & RMSEA & PNFI \\
\hline Desired Levels* & & & $\leq 3.0$ & $\leq 0.1$ & $\geq 0.6$ \\
\hline SEM Overall & 100 & $465.09(0.000,182)$ & 2.55 & 0.119 & 0.711 \\
\hline SEM Overall, with SOCLEV excluded & 100 & $221.70(0.000,101)$ & 2.19 & 0.105 & 0.786 \\
\hline SEM Developed Nations & 54 & $321.6(0.000,185)$ & 1.74 & 0.116 & 0.649 \\
\hline SEM Developing Nations & 56 & $452.4(0.000,184)$ & 2.46 & 0.166 & 0.498 \\
\hline
\end{tabular}

To examine the robustness of the SOCLEV factor, a second model was tested that is similar to the overall model, but excluding the SOCLEV factor and its observed variables. Results of this 3-factor model are similar to the overall model in the strong covariance between INVBT and GSLO and nonsignificant influence on INVBT on TECUTIL. However, the influence of GSLO is also non- significant on TECUTIL. The overall SEM goodness of fit is significant and similar to the full model. Since this model is overall weaker in its factor relationships, it reinforces that SOCLEV is important to include.

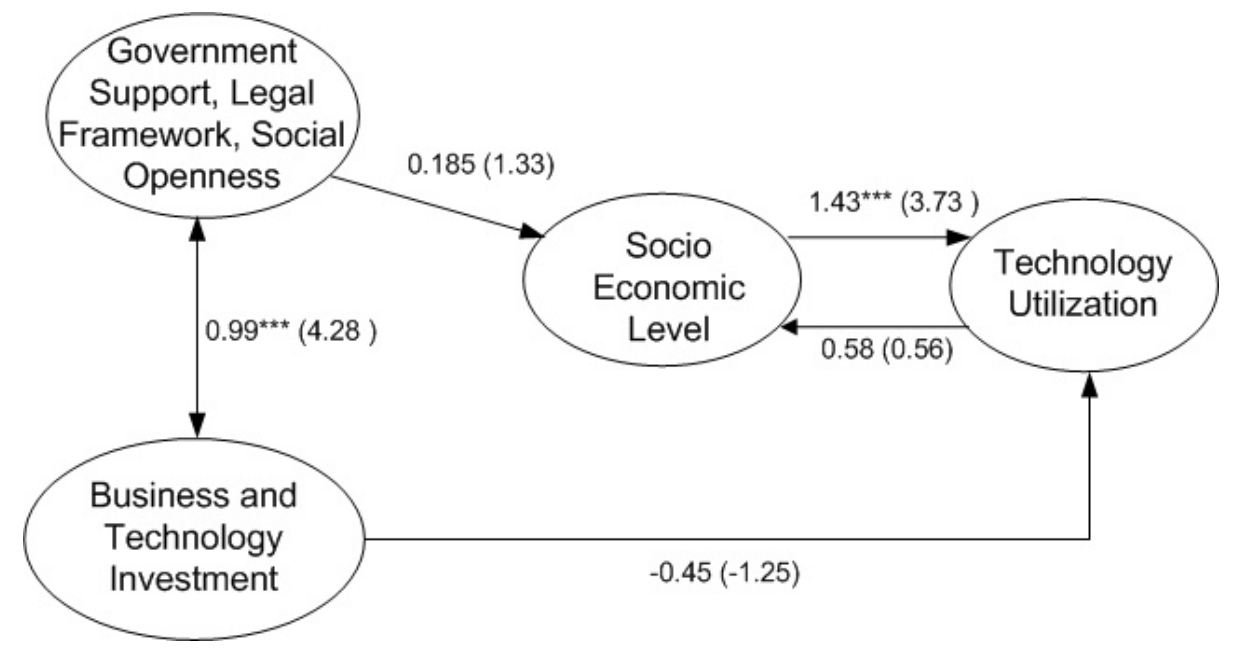

Figure 2. Standardized estimates from Non-recursive Structured Equation Model, Overall Sample

Potential differences of developed and developing nation subsamples were tested by introducing two more models, for developed and developing country subsamples. The purpose of doing this was to analyze whether the 4-factor model is supported for these sets of countries that differ considerable economically, socially, and technologically. Prior studies of developing nations [15] [36] [38], developed nations [37], and comparisons of both [34] [45] had noted a number of differences, such as greater importance of $R \& D$ as a correlate of technology in developed nations [34] and 
uncertainty avoidance as an inhibitor in developing counties [45].

The results for the subsamples are consistent with the overall model and in addition the pathway of influence from GSLO to SOCLEV to TECUTIL is strengthened. The overall goodness of fit for the submodels is somewhat stronger than for the overall model (see Table 1). For developed countries (see Figure 3, top), INVBT and GSLO co-vary significantly, while the strong pathway just mentioned is highly statistically significant. As with the overall model, the direct effect of INVBT on TECUTIL remains non-significant and slightly positive. Prior studies have shown that scientific research and creative activities are associated with technology adoption and use in developed nations [34]. However, those studies were qualitative or restricted in model scope, so the present use of broader SEM that includes the factors of SOCLEV and GSLO covarying with INVBT, may realize the impacts of INVBT on technology utilization more indirectly.

The findings for the model in 55 developing nations (Figure 3, bottom) are mostly similar but weaker than those for developed nations and particularly in the non significance of the covariance between INVBT and GSLO. The factors may not significantly co-vary because of a fundamental divergence of investment in business and technology from government legal, competitive, and internal support structure in developing nations. One reason is that these countries' investment in technology is increasingly external from such sources as foreign direct investment, technology transfer arrangements, joint ventures, and multinational companies that are somewhat distinctive from domestic government policies and frameworks. This disjunction in this model versus the developed nation model points to further research to try to discern and identify its causation. In spite of this disjunction, the pathway of GSLO influencing SOCLEV and in turn TECUTIL is comparable in strength to developed nations. The links in this pathway have been pointed to for developing countries in several prior studies [3][6]. For an economically disadvantaged, struggling country this implies the difficult step government strategic planners and leaders should consider of reducing control and red tape, adding freedoms and openness, which in turn help to stimulate educational advances, greater labor force participation including by women, and higher incomes, all of which contributes to enhanced technology utilization.
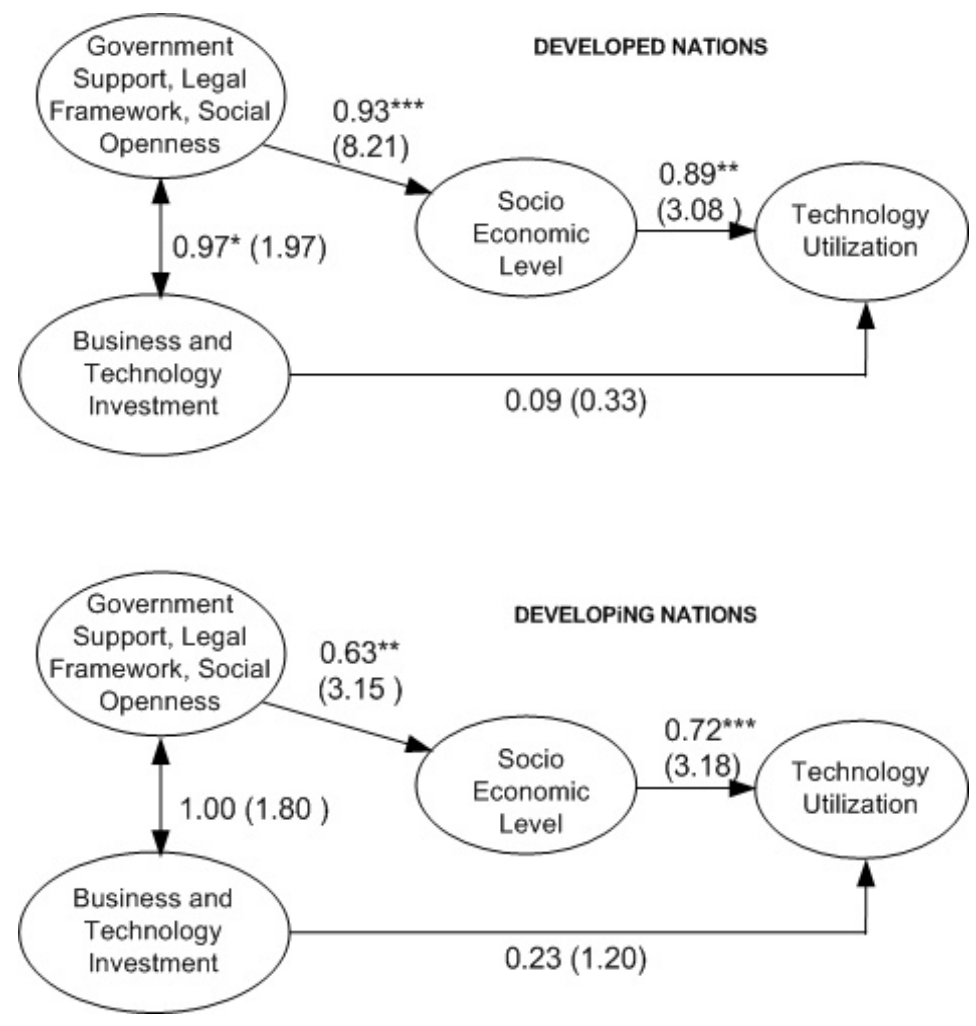

Figure 3. Standardized estimates from Structured Equation Models, Developed and Developing Nations 


\section{Conclusion}

This paper analyzed the relationships of socioeconomic factors, business and technology investment, and governmental support framework on technological usage of 110 countries. The conceptual framework is that the four factors are related in an overall model that impact the utilization of technology. Results show a strong pathway of influence from the government framework to socioeconomic level and in turn on technological level, which is consistent and even stronger for separate samples of developed and developing nations. The direct influence of business and technology investment on technology utilization is consistently weak. The findings are consistent with portions of prior literature studies, although SEM analysis has rarely been applied to the study of the "global digital divide," largely due to lack of large country samples up to recently.

The paper has the limitation that the unit of analysis is the country, rather than the individual or household. However, consistent individual or household data are not available for samples of 100 or more countries, and such large and varied samples might lead to conceptual challenges. The present study has sought to interpret the findings at the country level and not infer interpretation of results for smaller units of analysis.

Returning to the paper's research questions, the findings indicate the following:

Research Question 1. It is supported for all models examined, since the overall goodness of fit is demonstrated.

Research Question 2. Covariance of GSLO and INVBT is supported by the overall and developed nation models, but not for developing nations.

Research Question 3. The influence of GSLO on SOCLEV is supported only for the developed and developing country subsamples.

Research Question 4. The influence of SOCLEV on TECUTIL is supported only for the developed and developing country subsamples.

Research Question 5. There is no significance direct impact of INVBT on TECUTIL.

The research has fundamental policy implications, especially for the developing world. For government planners, it suggests longer-term steps involving changes in government prioritization of ICT, openness of society, democracy, and stable legal structure. There are perhaps higher-level reasons to take these steps such as to better the human condition, but technology is a beneficiary, and this research points to a pathway through the intermediate factor of improving social and economic conditions. China in recent years might exemplify this pathway, which is clearly now in process and not completed, but we can point to the loosening in historical tight autocratic control and the cracking open of some freedoms as a stimulus to economic growth, with technological level as a beneficiary. Government leaders in both developed and developing nations need to consider that investment alone in business and technology will not result in high national levels of technology use. Rather long-term and strong policies that improve educational openness, quality of instruction, women in the labor force, higher per capita income, and a more mature age structure with a higher proportion of working population will enable the society to succeed with technology utilization.

The study also implies that the developed nations similarly benefit by government support, quality legal framework, and societal openness leading to betterment in socioeconomic level and to technology utilization. This implies that economically advanced countries can also improve their technology utilization through policy prioritization of ICT, improved privacy and intellectual property laws; efficient, open business procedures; and greater societal openness. Examples of countries that demonstrate these factors are Australia, Ireland, the United Kingdom, and Scandinavian countries. Although their governance and socio-economic levels are already high, further improvement can occur through the pathway delineated. At the same time, this study implies that sheer investment size, R\&D strength, and financial sophistication have less impact on technology utilization, compared to the governmental and social factors mentioned. At the least, this study implies that business and technology investments need to be coupled and coordinated with governmental and societal priorities and initiatives, in order to advance a country's digital utilization level.

The present study implies that future research needs to address the links between technological change and socioeconomic factors, available resources, the role of government, multicultural content, behavior of population, corporate social responsibility, the building of communities, and social group compositions. Establishment of a comprehensive dialogue between different stakeholders in national and other communitiesgovernment, businesses, educational, institutions, citizens--can foster a unified approach to pathways 
such as appear in this research, with their potential benefits.

\section{References}

[1] Arbuckle, J.L. AMOS 16.0 Users Guide. SPSS Inc., Chicago, Illinois, 2007.

[2] Atkins, D.E. In Brown, J. S. and P. Duguid. The Social Life of Information, Harvard Business School Press, Boston, Massachusetts, 2000.

[3] Autor, D. L. L. F. Katz, and A.B. Krueger. "Computing Inequality: Have Computers Changed the Labor Market?" Quarterly Journal of Economics (113:4), November 1998. p. 1169-1213.

[4] Azari, R. and J. B. Pick. 2005. "Technology and Society: Socioeconomic Influences on Technological Sectors for United States Counties," International Journal of Information Management, (25:1), 2005, pp. 25-37.

[5] Baldwin R.E. and G.G. Cain. "Shifts in Relative U.S. Wages: The Role of Trade, Technology, and Factor Endowments," The Review of Economics and Statistics, November 2000. (82:4), pp. 580-595.

[6] Baliamoune-Lutz, M. "An Analysis of the Determinants and Effects of ECT Diffusion in Developing Countries." Information Technology for Development (10), 2003. p. 151-169.

[7] Barclay, C. and E.W. Duggan. "Rethinking the Digital Divide: Towards a Path of Digital Effectiveness," in Proceedings of the $41^{\text {st }}$ Hawaii International Conference on System Sciences-2008.

[8] Bollen, K.A. and J.S. Long (Eds.) Testing Structural Equation Models. Sage Publications, Newbury Park, California, 1993.

[9] Breshnan, T. "Information Technology, Workplace Organization and the Demand for Skilled Labor: Firm Level Evidence," 1999. NBER Working Paper, No.7136.

[10] Burtless, G. "International Trade and the Rise in Earnings Inequality," Journal of Economic Literature (33:2) June 1995. p. 800-816.

[11] Byrne, B.M. Structural Equation Modeling with AMOS, Lawrence Erlbaum Associates Publishers, Mahwah, New Jersey, 2001.
[12] Carmines, E.G. \& J.P. McIver. "Analyzing Models with Unobserved Variables," in Bohrnstedt, G.W. and Borgatta, E.F. (Eds.). Social Measurement: Current Issues, Beverly Hills, CA, Sage Publications, 1981.

[13] Carr, D. “The Global Digital Divide," Context (6:3), Spring, 2007. p. 58.

[14] Castells, M. The Rise of the Network Society, Blackwell Publishers Ltd, Oxford, England, 1996.

[15] Chinn, M.D. and R.W. Fairlie. "The Determinants of the Global Digital Divide: A Cross-country Analysis of Computer and Internet Penetration," Oxford Economic Papers (59), 2007, pp. 16-44.

[16] Dasgupta, S., S. Lall, and D. Wheeler. "Policy Reform, Economic Growth and the Digital Divide." Oxford Development Studies (33:2), 1998. p. 229-243.

[17] Danowitz, A., Y. Nassef, and S.E. Goodman. "Cyberspace Across the Sahara: Computing in North Africa," Communications of the ACM 38(12), 1995, pp. 23-28.

[18] Deardorff, A.V. "Technology, Trade, and Increasing Inequality: Does the Cause Matter for the Cure?" Journal of International Economic Law, 1998. p. 353-376.

[19] Dutta, S., Lanvin, B., \& Paua, F. Global Information Technology Report 2006-2007: Readiness for the Networked World, New York, NY: Oxford University Press, New York, New York, 2007.

[20] Dutta, S.. "Estonia: A Sustainable Success in Networked Readiness." The Global Information Technology Report 2006-2007, Connecting to the Networked Economy, Dutta, S., and I. Mia (Eds.), New York, NY, Palgrave Macmillan, 2007, pp. 81-90.

[21] Florida, Richard. The Flight of the Creative Class. HarperBusiness, New York, 2005.

[22] Freedman, J.B. and J.C. Henerson. "Digital Usage Behavior: a Sense Making Perspective," in Proceedings of the $41^{\text {st }}$ Hawaii International Conference on System Sciences-2008.

[23] Guillen, M.E. \& S.I Suarez. "Explaining the Global Digital Divide: Economic, political and sociological drivers of cross-national internet use." Social Forces (84:2), December 2005. p. 681-708. 
[24] Harrington, M. The International Thesaurus of Quotations by Rohda, Thomas Tripp, Harper and Row.

[25] Haskel, J. and M.J. Slaughter.. Trade, Technology and U.K. Wage Inequality," The Economic Journal, 111, January, 2001. p. 163-187.

[26] James, J. "Digital Divide Complacency: Misconceptions and Dangers," The Information Society (24) 2008. p. 54-61.

[27] Johnson, G.E. "Changes in Earning Inequality," The Journal of Economics Perspectives (11:2) Spring 1997. p. 41-54.

[28] Korupp, S.E., and M. Szydlik, M. "Causes and trends of the digital divide," European Sociological Review (21:4), 2005, pp. 409-422.

[29] Krugman, P.R. "Technology, Trade, and Factor Prices," NBER Working Paper, No. 5395, Cambridge, Mass 1995.

[30] Liu, M.-C., \& G. San. "Social Learning and Digital Divides: A Case Study of Internet Technology Diffusion. Kyklos, 59:2, p. 307-321.

[31] Norris, P., Bennett, W.L., and Entman, R.M. (Eds). Digital Divide: Civic Engagement, Information Poverty, and the Internet Worldwide. Cambridge University Press, Cambridge, England, 2001.

[32] OECD. $21^{\text {st }}$ Century Technologies: Promises and Perils of a Dynamic Future, OECD, Paris, France, 1998.

[33] Ono, H. and M. Zavodny. "Digital Inequality: A Five Country Comparison Using Microdata," Social Science Research (36:3), September 2007. p. 11351155.

[34] Pick, J. B., and R. Azari. "Global Digital Divide: Influence of Socioeconomic, Governmental, and Accessibility Factors on Information Technology." Information Technology for Development 14(2), 2008, pp. 91-115.

[35] Quibria, M.G., S.N. Ahmed, T. Tschang, and M.L. Reyes-Macasaquit. "Digital Divide: Determinants and Policies with Special Reference to Asia." Journal of Asian Economics (13), 2003. p. 811-825.

[36] Raven, V.P., X. Huang, and B. B. Kim. "EBusiness in Developing Countries: A Comparison of
China and India," International Journal of E-Business Research (3:1), 2008, pp. 91-108.

[37] Robison, K.K., and M.W. Crenshaw. "Postindustrial Transformations and Cyber-Space: A CrossNational Analysis of Internet Development," Social Science Research (31), 2002, pp. 91-108.

[38] Sharma, S.K., and J.N.D. Gupta. "SocioEconomic Influences of E-Commerce Adoption," Journal of Global Information Technology Management (6:3), 2003, pp. 3-21.

[39] Van Dijk, J. A. G. M. The Deepening Divide: Inequality in the Information Society, Sage Publication, London, England, 2005.

[40] Wallsten, S. "Regulation and Internet Use in Developing Countries," Economic Development and Cultural Change (53:2), January 2005. p. 501-523.

[41] Warschauer, M. "Dissecting the 'Digital Divide:'A Case Study of Egypt." The Information Society (19), 2003, pp. 297-304.

[42] Wilhelm, A. Digital Nation: Toward an Inclusive Information Society, MIT Press, Cambridge, Massachusetts, 2004.

[43] World Bank. The World Development Indicators, World Bank, Washington, D.C., 2007.

[44] World Economic Forum. Annual Report of the Global Digital Divide Initiative. Geneva: World Economic Forum 2002.

[45] Zhao, H., K. Sueng, T. Suh, and J. Du. "Social Institutional Explanation of Global Internet Diffusion: A Cross-Country Analysis," Journal of Global Information Management (15:2), April-June 2007. p. 28-55. 